'Instituto Nacional de Câncer (INCA), Rio de Janeiro, RJ, Brasil

Financial support: None. Conflicts of interest: No conflicts of interest declared concerning the publication os this article. Submitted: July 19, 2017. Accepted: November 14, 2017.

The study was carried out at Instituto Nacional de Câncer (INCA), Rio de Janeiro, RJ, Brasil.

\section{Experience with the introduction of Transoral Robotic Surgery (TORS) at an oncologic hospital of the Brazilian Unified Public Health System (SUS)}

\author{
Ruy Gomes Neto ${ }^{*}$, Fernando Luiz Dias¹, Roberto Rêgo Monteiro de Araújo Lima1, \\ Ullyanov Bezerra Toscano ${ }^{1}$, Emilson Queiroz de Freitas ${ }^{1}$, Terence Pires de Farias ${ }^{1}$, \\ Izabella Costa Santos', Bernardo Cacciari Peryasssu', \\ Bruno Alburquerque Sousa ${ }^{1}$, Julia Mattos Levi ${ }^{1}$
}

\begin{abstract}
Introduction: Transoral Robotic Surgery (TORS) has emerged for treatment of oropharyngeal and supraglottic larynx tumors due to the increase of oropharyngeal cancer caused by HPV. Objective: To demonstrate the oncological results achieved with this technology. Methods: The study was retrospective, with 132 cases of patients submitted to TORS at our institution - 101 men and 31 women; 114 malignant. 65 patients in the malignant group received TORS as first-line treatment, and 44, as salvage treatment; 5 patients were excluded due to another treatment option. $10.61 \%$ of patients presented complications - the most common was bleeding. However, only 3 patients had to be reoperated. The mean time of enteral tube use was 14.2 days, and the mean time of tracheotomy was 29.77 days. By the end of the study, all patients had been dependent on enteral tube and tracheotomy. The mean time of hospitalization was 4.5 days; the mean total time of surgery was 65.4 minutes - 19.6 for docking and set-up, and 45.8 for console operation. Results: Among a total of 132 surgeries, our complication rate was of $10.61 \%$, whereas 3 patients required reoperation. All patients had the enteral catheter and tracheotomy removed. The overall survival of patients submitted to TORS as first-line treatment was $86.2 \%$, and disease-free survival, $83.0 \%$. Among patients undergoing robotic surgery as salvage therapy, the overall survival was of $51.5 \%$, and disease-free survival in the same period, of $42.2 \%$. Conclusion: TORS is safe and it is usually possible to obtain negative surgical margins for malignant oropharyngeal and supraglottic larynx tumors. Use of this treatment was successfully introduced in a public hospital in Brazil.
\end{abstract}

Keywords: head and neck neoplasms; oropharynx; oropharyngeal neoplasms; robotics.

\section{Introduction}

Robotic surgery emerged to aid surgical procedures in 1985 with the development of its first robot ${ }^{1}$. Since then, it has been employed by different medical specialties, whereas its benefits are more well-established in urology². O'Malley and Weinstein have demonstrated the safe use of transoral robotic 
surgery (TORS) in oropharyngeal and laryngeal tumors ${ }^{3,4}$ in humans by means of the daVinci (Intuitive Surgical, Sunnyvale, CA) system ${ }^{5,6}$.

At the same time this new technology for head and neck surgery was introduced, a progressive increase in incidence of oropharyngeal tumors particularly associated with HPV infection - was observed in the United States. About 12,000 new cases were diagnosed in 20117, mostly in the tonsil and base of tongue. In Brazil, Instituto Nacional de Câncer (INCA) estimates 11,140 new cases among men and 4,350 new cases among women for 2016.

The treatment options for oropharyngeal tumors range from surgery to radiation therapy, whereas a multimodal approach that combines these two, or chemo- and radiation therapy ${ }^{8}$, can also be considered. In this scenario, transoral robotic surgery provides additional benefits, such as shorter time in surgery, hospitalization and dependence on enteral feeding tubes and tracheotomy. All of these factors, in addition to the reduction of the radiation therapy dose, help to reduce morbidity without compromising oncological outcomes compared to conventional surgery ${ }^{9-11}$.

Our objective is to demonstrate the experience of the Transoral Robot Surgery (TORS) team under the Brazilian Unified Public Health System (SUS) at Instituto Nacional de Câncer (INCA) since 2012, demonstrating that the technique is safe and reduces morbidity of patients. For such, we have analyzed the period of use of feeding tubes, tracheotomy, and hospitalization, as well as the occurrence of complications in surgical procedures performed on benign pathologies and oropharyngeal cancer. We intend to demonstrate the oncological outcomes obtained in patients with oropharyngeal carcinoma who have received TORS as both first line and salvage treatment within a period of at least 12 months.

\section{Methodology}

\section{Inclusion criteria}

Patients who received transoral robotic surgery and treatment at Seção de Cirurgia de Cabeça e Pescoço do Instituto Nacional de Câncer - INCA [Department of Head and Neck Surgery at INCA] between 2012 and 2015 were selected for the study group.

\section{Exclusion criteria}

Cases with insufficient data about the treatments used.

\section{Technical data}

Analysis of medical records, in which data concerning time of surgery, robot docking time and surgical procedure time was collected.

\section{Clinical and pathological variables}

The analysis took the following variables into account: primary tumor site and cervical metastases; duration of treatment; time between treatment of primary tumor and detection of recurrence (metastatic, local, and regional 
disease); disease-free survival rate; time between treatment and death; overall survival rate; type of treatment; treatment used in case of recurrence; postoperative complications; surgical margins (ampliated or free margins); time of use of feeding tube; time of tracheotomy.

\section{Follow-up}

By consulting patients' medical records, the date of surgical treatment and of the last control consultation was noted, as well as the patients' condition according to their stage: alive and disease-free, death by disease, or death by another cause. In cases of recurrence, the date of occurrence was also noted, as well as the duration of follow-up, in months. Our period of follow-up was of 3 to 55 months, 23.5 months on average.

\section{Methodology: retrospective cohort study}

\section{Surgical methodology}

The da Vinci Surgical Robot (Intuitive Surgical, Sunnyvale, California, USA) was used for all of the procedures. Patients' eligibility for this type of procedure was determined by a second assessment performed by a specialist in robotic surgery by means of a physical exam and indirect laryngoscopy. In cases where the presence of nasopharynx lesion was not clearly determined, a nasofibroscopy was performed in all patients, in addition to a tomography of the oral cavity and oropharynx. None of these patients presented characteristics such as nasopharynx invasion, impairment of vessels in the parapharyngeal space, and bone invasion. Mouth opening was also a decisive factor for recommendation of robotic surgery.

All patients were submitted to general anesthesia. Intubation was either oral or nasal, depending on the tumor location and at the surgeon's discretion. The FK Retractor (Olympus) was the retractor of choice for these procedures, although Dingman was also used in some cases. The retractor was positioned so that the tumor edge was entirely at sight. For this purpose, the FK Retractor is provided with blades of different curvatures, sizes, and shapes in order to expose the base of the tongue all the way to the laryn $x^{5}$. Then, asepsis and antisepsis of both the patient's oral cavity and face was performed; sterile fields were put in place. The system then approaches the patient on their right hand side at a 45-degree angle - we always use 0-degree optics; one of the system's arms is provided with Maryland, and the other, with the monopolar clamp. The surgeon performed the procedure from the console, while an assistant stood by the oral cavity with the suction device and clamp - in case it was necessary to perform hemostasis. After block resection of the lesion, the resection margins were assessed by frozen section; hemostasis was revised, and biological glue was applied. At this moment, according to the type and size of the resection, tracheotomy was performed, and an enteral feeding tube placed. 


\section{Statistical analysis}

Statistical analyses were performed with software SPSS version 22 (SPSS Inc., Chicago, IL). The overall survival (defined as the length of time from the date of treatment initiation to the date of death) and disease-free survival (defined as the length of time from treatment to recurrence) were estimated by means of the Kaplan-Meier method; the survival curves were compared by means of the Log-rank test. We have also looked into the correlation between the variables described above and overall survival (OS). The statistical tests below were used to assess the correlation between variables: T-test (categorical versus numerical variable), Chi-square. A $p$ value equal or below 0.05 was considered statistically significant.

\section{Results}

One hundred and thirty-two surgical procedures were carried out by the da Vinci system between 2012 and 2015. The population's characteristics are described in Table 1. Among the total, 114 resections were performed on malignant tumors representing the study's casuistic upon assessment of oncological outcomes, 18 resections were performed on benign tumors, which have been accounted for upon assessment of the procedure's morbidity, time of hospitalization and surgery. The predominant histopathology was squamous cell carcinoma, followed by carcinoma in situ. Other less common histological types have also been found, as shown in Table 2 - which also shows the degree of differentiation of the squamous cell carcinomas.

Table 1. General characteristics of the study's population.

\begin{tabular}{lcc}
\hline Gender & & \\
\hline Male & 101 & $76.52 \%$ \\
\hline Female & 31 & $23.48 \%$ \\
\hline Location of Robotics & 70 & \\
\hline Tonsil & 49 & $33.03 \%$ \\
\hline Base of tongue & 3 & $2.27 \%$ \\
\hline Posterior wall of the oropharynx & 9 & $6.82 \%$ \\
\hline Supraglottis & 1 & $0.76 \%$ \\
\hline Epiglottic fold & & $47.73 \%$ \\
\hline Side & 63 & $39.39 \%$ \\
\hline Right-hand & 52 & $12.88 \%$ \\
\hline Left-hand & 17 & \\
\hline Bilateral & 61.06 & \\
\hline Mean age & &
\end{tabular}


Table 2. Histological types.

\begin{tabular}{|c|c|c|}
\hline \multicolumn{3}{|c|}{ Patients } \\
\hline Malignant & 114 & $86.4 \%$ \\
\hline Benign & 18 & $13.6 \%$ \\
\hline Total & 132 & $100.0 \%$ \\
\hline \multicolumn{3}{|l|}{ Malignant } \\
\hline Squamous cell carcinoma & 100 & $87.9 \%$ \\
\hline Carcinoma in situ & 4 & 3.5 \\
\hline Adenoid Cystic Carcinoma & 2 & $1.7 \%$ \\
\hline Mucoepidermoid Carcinoma & 2 & $1.7 \%$ \\
\hline Lymphoepithelioma & 2 & $1.7 \%$ \\
\hline Lymphoma & 2 & $1.7 \%$ \\
\hline Papillary Carcinoma & 1 & $0.9 \%$ \\
\hline Neuroendocrine Carcinoma & 1 & $0.9 \%$ \\
\hline \multicolumn{3}{|l|}{ Benign } \\
\hline Hyperplasia & 14 & $77.6 \%$ \\
\hline Dysplasia & 1 & $5.6 \%$ \\
\hline Cicatrization process & 1 & $5.6 \%$ \\
\hline Osteoma & 1 & $5.6 \%$ \\
\hline Pleomorphic Adenoma & 1 & $5.6 \%$ \\
\hline \multicolumn{3}{|c|}{ Degree of Differentiation of Squamous Cell Carcinomas } \\
\hline Well differentiated & 3 & $3 \%$ \\
\hline Moderate & 79 & $79 \%$ \\
\hline Poorly differentiated & 18 & $18 \%$ \\
\hline
\end{tabular}

Patients presenting lymphoepithelial carcinoma, lymphoma, and papillary carcinoma were excluded from the poll of patients with malignant tumors for analysis of the oncological variables due to the presence of other therapeutic modalities. Thus, the analysis considered 109 patients altogether. Among these, 65 (59.63\%) underwent TORS as their first-line treatment; on the other hand, $44(40.37 \%)$ presented recurring tumors and the surgery was a salvage procedure. The use of neck dissection, or absence thereof, is shown in Table 3.

Taking into account the patients submitted to TORS as first-line treatment alone, $38(58.46 \%)$ presented tumors located at the tonsil, $20(30.77 \%)$ at the base of the tongue, 6 at the supraglottal larynx, and only 1 at the posterior wall (Table 4). According to TNM [Classification of Malignant Tumors], most patients submitted to TORS were on stage T1 (43\%) or T2 (40\%), where 27 cases (41.54\%) were classified as N0, as shown in Table 5. 
Table 3. Neck dissection.

\begin{tabular}{lcc}
\hline & \multicolumn{2}{c}{ Patients } \\
\hline No & 51 & $46.79 \%$ \\
\hline Selective & 16 & $14.68 \%$ \\
\hline Modified radical neck dissection & 40 & $36.70 \%$ \\
\hline Bilateral & 2 & $1.83 \%$ \\
\hline Total & 109 & $100.00 \%$ \\
\hline Salvage Procedures & & \\
\hline No & 35 & $15.90 \%$ \\
\hline Selective & 2 & $100.00 \%$ \\
\hline Modified radical neck dissection & 7 & \\
\hline Total & 44 & $24.62 \%$ \\
\hline Initial Treatment & & $21.54 \%$ \\
\hline No & 16 & $50.77 \%$ \\
\hline Selective & 14 & $3.09 \%$ \\
\hline Modified radical neck dissection & 33 & $100.00 \%$ \\
\hline Radical neck dissection & 2 & \\
\hline Total & 65 & \\
\hline
\end{tabular}

Table 4. Location of tumors submitted to initial treatment.

\begin{tabular}{lcc} 
& \multicolumn{2}{c}{ Patients } \\
\hline Tonsil & 38 & $58.46 \%$ \\
\hline Base of tongue & 20 & $30.77 \%$ \\
\hline Posterior wall & 1 & $1.54 \%$ \\
\hline Supraglottis & 6 & $9.23 \%$ \\
\hline Total & 65 & $100.00 \%$ \\
\hline
\end{tabular}

Most patients submitted to TORS as salvage surgery presented primary tumors at the tonsil (17 cases, 38.64\%), followed by the larynx (11 cases, 25\%), and base of tongue ( 5 cases, $11.36 \%$ ), as shown in Table 6 . In these cases, the location of recurrence, or second primary - i.e. in most cases, the location of robotic resection -, was the base of the tongue (50\% of cases), followed by the tonsil (38.64\%), supraglottis (6.82\%), and posterior wall (2 cases).

As to staging of tumors submitted to salvage surgery, most of them were classified as T2, with $45.45 \%$ of the cases ( 20 patients), followed by $\mathrm{T} 1$, with 
Table 5. Classification of patients submitted to initial treatment.

\begin{tabular}{ccc} 
& \multicolumn{2}{c}{ Patients } \\
\hline Tis & 1 & $1.54 \%$ \\
\hline T1 & 28 & $43.08 \%$ \\
\hline T2 & 26 & $40.00 \%$ \\
\hline T3 & 8 & $12.30 \%$ \\
\hline T4 & 2 & $3.08 \%$ \\
\hline N0 & 28 & $43.07 \%$ \\
\hline N1 & 13 & $20.00 \%$ \\
\hline N2a & 5 & $7.69 \%$ \\
\hline N2b & 15 & $23.10 \%$ \\
\hline N2c & 3 & $4.61 \%$ \\
\hline N3 & 1 & $1.53 \%$ \\
\hline M0 & 65 & $100.00 \%$ \\
\hline M1 & 0 & $0.00 \%$ \\
\hline Total & 65 & $100.00 \%$
\end{tabular}

Table 6. Location of salvage procedures.

\begin{tabular}{lcc} 
Location of Robotics & & \\
\hline Tonsil & 17 & $38.64 \%$ \\
\hline Base of tongue & 22 & $50.00 \%$ \\
\hline Posterior wall & 2 & $4.55 \%$ \\
\hline Supraglottis & 3 & $6.81 \%$ \\
\hline Primary Location & & \\
\hline Tonsil & 11 & $25.00 \%$ \\
\hline Base of tongue & 5 & $11.36 \%$ \\
\hline Posterior wall & 1 & $2.28 \%$ \\
\hline Larynx & 11 & $25.00 \%$ \\
\hline Hypopharynx & 6 & $13.64 \%$ \\
\hline Oral Cavity & 6 & $13.64 \%$ \\
\hline Out of HN region & 1 & $2.27 \%$ \\
\hline Nasopharynx & 1 & $2.27 \%$ \\
\hline Soft Palate & 1 & $2.27 \%$ \\
\hline Occult Primary & 1 & $2.27 \%$ \\
\hline Total & 44 & $100.00 \%$ \\
\hline
\end{tabular}


$40.91 \%$ of the cases. With regard to the neck condition, $90.91 \%$ presented negative neck upon physical examination and imaging test (Table 7).

All of the patients underwent frozen section intraoperative biopsy for assessment of margins, as described in Table 8.

Table 7. Staging of patients submitted to salvage surgery.

\begin{tabular}{ccc}
\hline \multicolumn{3}{c}{ Patients } \\
\hline T1 & 18 & $40.91 \%$ \\
\hline T2 & 20 & $45.45 \%$ \\
\hline T3 & 6 & $13.64 \%$ \\
\hline T4 & 0 & $0.00 \%$ \\
\hline Nis & 0 & $0.00 \%$ \\
\hline N1 & 40 & $90.91 \%$ \\
\hline N2a & 2 & $4.55 \%$ \\
\hline N2b & 1 & $2.27 \%$ \\
\hline N2c & 1 & $2.27 \%$ \\
\hline N3 & 0 & $0.00 \%$ \\
\hline M0 & 0 & $0.00 \%$ \\
\hline M1 & 44 & $100.00 \%$ \\
\hline Total & 0 & $0.00 \%$ \\
\hline & 44 & $100.00 \%$
\end{tabular}

Table 8. Surgical margins.

\begin{tabular}{lcc}
\hline General & \multicolumn{2}{c}{ Patients } \\
\hline Negative & 63 & $57.80 \%$ \\
\hline Negative after second resection & 38 & $34.86 \%$ \\
\hline Positive & 8 & $7.34 \%$ \\
\hline Total & 109 & $100.00 \%$ \\
\hline Initial Treatment with TORS & & \\
\hline Negative & 44 & $67.69 \%$ \\
\hline Negative after second resection & 18 & $27.69 \%$ \\
\hline Positive & 3 & $100.00 \%$ \\
\hline Total & 65 & \\
\hline Salvage Procedures & & $43.19 \%$ \\
\hline Negative & 19 & $45.45 \%$ \\
\hline Negative after second resection & 20 & $11.36 \%$ \\
\hline Positive & 5 & $100.00 \%$ \\
\hline Total & 44 &
\end{tabular}


Among the patients submitted to TORS as first-line treatment, $50.77 \%$ of cases were referred to adjuvant radiation therapy, $6.15 \%$ underwent concomitant chemo- and radiation therapy after robotic resection, and $43.08 \%$ did not require any supplementary treatment.

In order to assess the complication rate, we took all of the 132 patients submitted to robotic surgery into account, including patients presenting benign pathologies. The most common complication was bleeding; the remainder are described in Table 9.

Patients' morbidity was assessed by means of dependence on the enteral feeding tube, or lack thereof, and the need for tracheotomy. Since we used routine enteral feeding in most patients submitted to robotic surgery for a minimum of 10 days, it was possible to assess dependence on the tube from this point. Thus, we found a tube dependence rate in $50 \%$ of patients, whereas all patients who underwent TORS have been rehabilitated at some point during follow-up, and all of them had the enteral catheter removed.

Tracheotomy was necessary for 39 (29.55\%) of patients, whereas most of them were recommended during the TORS. Within 24 hours after the procedure, it was necessary to perform an urgent tracheotomy in one patient, whereas 7 patients had already been permanently tracheostomized due to previous treatment for the primary tumor. All of the patients, except those permanently tracheostomized from previous primary laryngeal tumor treatment, have been decannulated at some point of follow-up. The length of time of tube and tracheotomy dependence are described in Table 10.

Patients' time in hospital varied from 24 hours to 41 days, 4.5 days on average. The total time of surgery in minutes varied between 15 and 238, a mean of 65.4 minutes and median of 55 minutes. Table 11 shows the time in surgery, discriminating between the time of robot set-up and on the console, which was 45.8 minutes and 19.6 minutes on average, respectively (Table 11).

Patients presenting malignant tumors were followed-up for a period of 3 to 55 months - 23.5 months on average. In this period, $29.36 \%$ of patients presented recurrence. Among these, $75 \%$ were local recurrences, $15.63 \%$, regional, and $9.38 \%$, distant. Taking into account only patients submitted to TORS - whether or not followed by adjuvant treatment - as first-line treatment, only 9 patients (13.85\%) experienced tumor recurrence. Among these, 4 (44.44\%) were local, 2 (22.22\%) were regional, and 3 (33.33\%) were distant. On the other hand, patients submitted to salvage surgery

Table 9. Complications.

\begin{tabular}{lcc}
\hline Bleeding & $\mathbf{8}$ & $\mathbf{6 . 0 6 \%}$ \\
\hline Trismus & 4 & $3.03 \%$ \\
\hline Local Infection & 1 & $0.76 \%$ \\
\hline Pneumonia & 1 & $0.76 \%$ \\
\hline Total & 14 & $10.61 \%$ \\
\hline Total of Surgical Procedures & 132 & $100.00 \%$ \\
\hline
\end{tabular}


Table 10. Morbidity.

\begin{tabular}{lcccc} 
& \multicolumn{2}{c}{ Patients } & \multicolumn{2}{c}{ Time - Days } \\
\cline { 4 - 5 } & & & Mean & Median \\
\hline Feeding Tube & 66 & $50.00 \%$ & 14.2 & 10.5 \\
\hline Tracheotomy & 39 & $29.55 \%$ & 29.77 & 15 \\
\hline Total & 132 & $100.00 \%$ & & \\
\hline
\end{tabular}

Table 11. Surgical procedure.

\begin{tabular}{lcc} 
& Mean & Median \\
\hline Time of Hospitalization, in days & 4.5 & 4.0 \\
\hline Set-up Time & 19.6 & 20.0 \\
\hline Time on Console & 45.8 & 35 \\
\hline Time of Surgery & 65.4 & 55.0 \\
\hline
\end{tabular}

presented a recurrence rate of $52.27 \%$ ( 23 cases among 44 surgeries), where $86.96 \%$ were local (20 cases) and $13.04 \%$ were regional (3 cases). In the salvage group, none of the patients presented distant recurrence (Table 12).

Among the 132 patients with both malignant and benign tumors submitted to TORS, 34 (25.76\%) died at some point, where $76.47 \%$ of deaths were due to a tumor recurrence, $14.71 \%$ to clinical causes, 1 patient presented a second primary tumor, and 2 patients with benign histopathology at TORS died from causes related to the underlying disease out of the head and neck region. Only 1 patient died while in hospital from blood dyscrasia due to previous coagulopathy (Table 13).

Taking into account patients submitted to primary treatment alone, 11 (16.92\%) died -7 (63.64\%) from recurrence, 3 of clinical causes, and 1 of a second primary.

With regard to patients submitted to salvage TORS, 21 (47.73\%) died, 19 (90.48\%) from recurrence, and 2 of clinical causes (9.52\%).

The oncological outcomes were divided into 2 groups. The patients submitted to transoral robotic surgery as first-line treatment presented overall survival of $86.2 \%$ in 24 months, and of $74.2 \%$ in 36 months with a mean survival estimate of 48.9 months (Figure 1). The progression-free survival for the same period was $88.5 \%$ in 24 months and $86.0 \%$ in 36 months, with a mean progression-free survival of 48.1 months (Figure 2). We have also assessed specific survival, which was $91.5 \%$ in 24 months and $83.1 \%$ in 36 months, with a mean survival estimate of 48.6 months for these patients (Figure 3 ). In addition, by comparing specific survival to the $T$ staging system, we found a specific survival of $90.3 \%$ in T1 and T2 in 24 months and $84.7 \%$ in 36 months with a mean estimate of specific survival in this group of 51.1 months. In T3 and T4, we highlight a specific survival of 100\% in 24 months and $75 \%$ in 36 months, 
Table 12. Recurrence.

\begin{tabular}{lcc}
\hline Initial Treatment & & \\
\hline Local & 4 & $44.4 \%$ \\
\hline Regional & 2 & $22.1 \%$ \\
\hline Distant & 3 & $33.3 \%$ \\
\hline Total & 9 & $100.0 \%$ \\
\hline Salvage Procedures & & \\
\hline Local & 20 & $86.60 \%$ \\
\hline Regional & 3 & $13.40 \%$ \\
\hline Distant & 0 & $100 \%$ \\
\hline Total & 23 & \\
\hline
\end{tabular}

Table 13. Deaths.

\begin{tabular}{lcc}
\hline Initial Treatment & & \\
\hline Recurrence & 7 & $63.64 \%$ \\
\hline Clinical & 3 & $27.27 \%$ \\
\hline Second Primary & 1 & $9.09 \%$ \\
\hline Total & 11 & $100.00 \%$ \\
\hline Salvage Procedures & & \\
\hline Recurrence & 19 & $90.48 \%$ \\
\hline Clinical & 2 & $9.52 \%$ \\
\hline Second Primary & 0 & $0.00 \%$ \\
\hline Total & 21 & $100.00 \%$ \\
\hline Benign & 2 & $5.88 \%$ \\
\hline Total of deaths & 34 & $25.76 \%$ \\
\hline
\end{tabular}

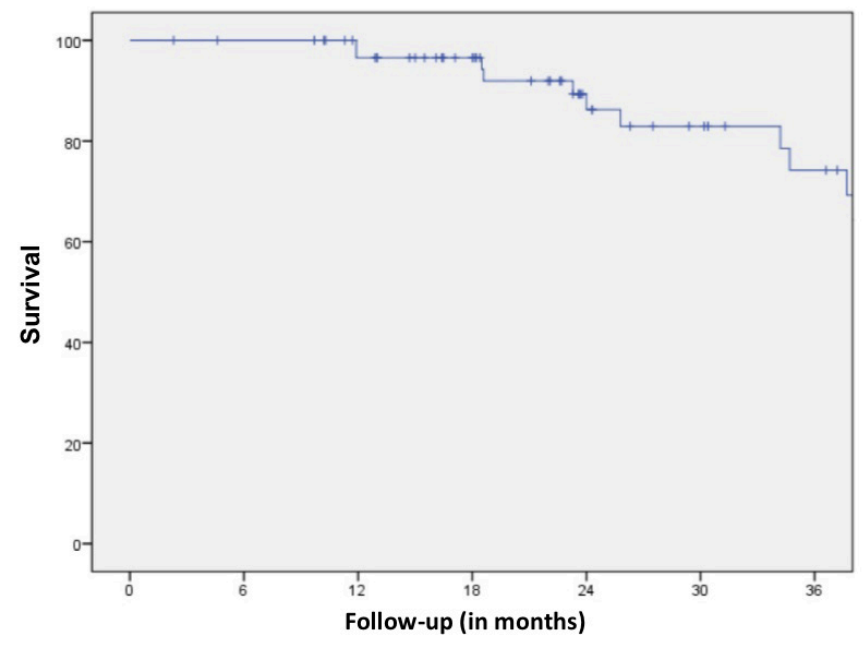

Figure 1. Initial treatment: overall survival. 


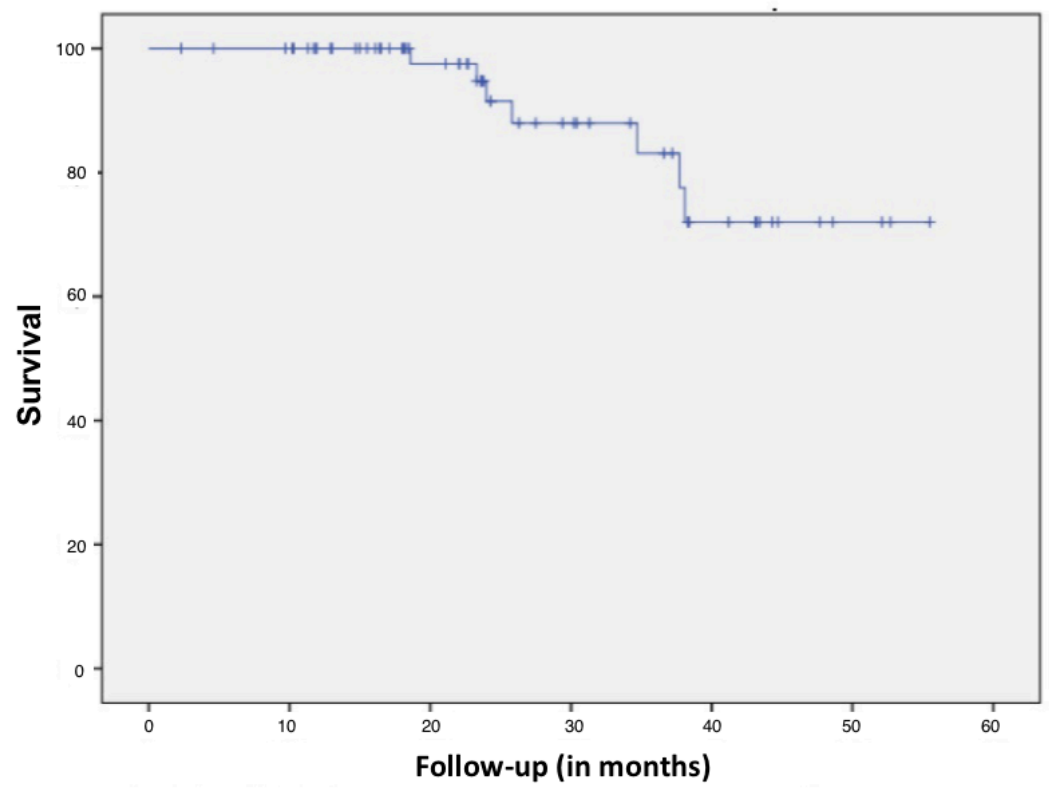

Figure 2. Initial treatment: specific survival.

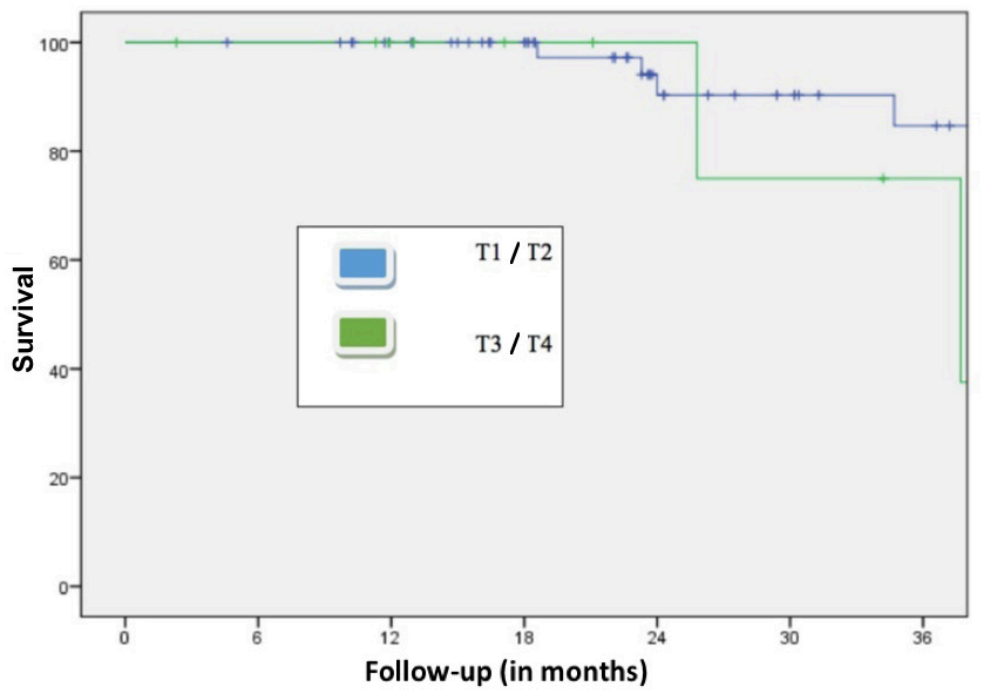

Figure 3. Specific survival according to staging at initial treatment.

with a mean specific survival estimate of 34.8 months (Figure 4). Considering patients submitted to robotic surgery as salvage treatment, we found an overall survival of $68.4 \%$ in 24 months and $23.9 \%$ in 36 years, with the mean estimate of overall survival of 28.2 months (Figure 5). Disease-free survival in 24 months was of $49.2 \%$, and in 36 months, of $32.1 \%$ with an estimate of disease-free survival of 23.9 months (Figure 6). On the other hand, specific survival in 24 months was $71.9 \%$, and in 36 months, $25.1 \%$, with a mean specific survival 
estimate of 29.3 months (Figure 7). We have also calculated the specific survival according to the stage classification. Patients with T1 and T2 presented specific survival of $71.9 \%$ in 24 months and $21.4 \%$ in 36 months, with a specific survival estimate of 29.2 months. Patients with T3 and T4 presented specific survival in 24 months of 75\%, and in 36 months, of 50\%; the specific survival estimate for this group was 30 months.

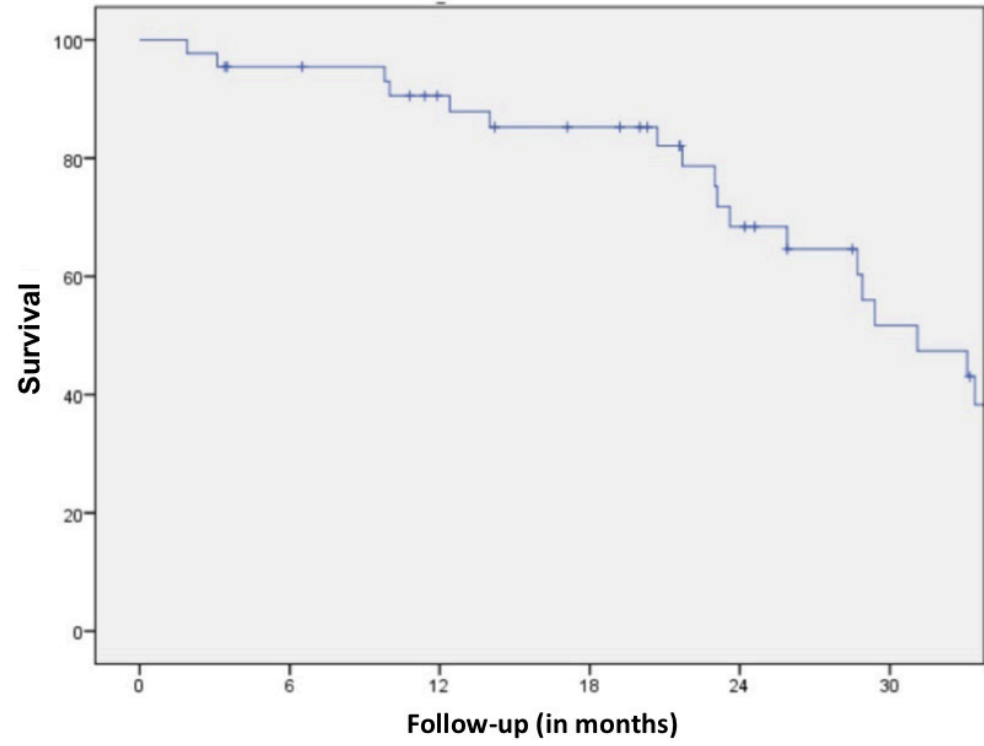

Figure 4. Salvage: overall survival.

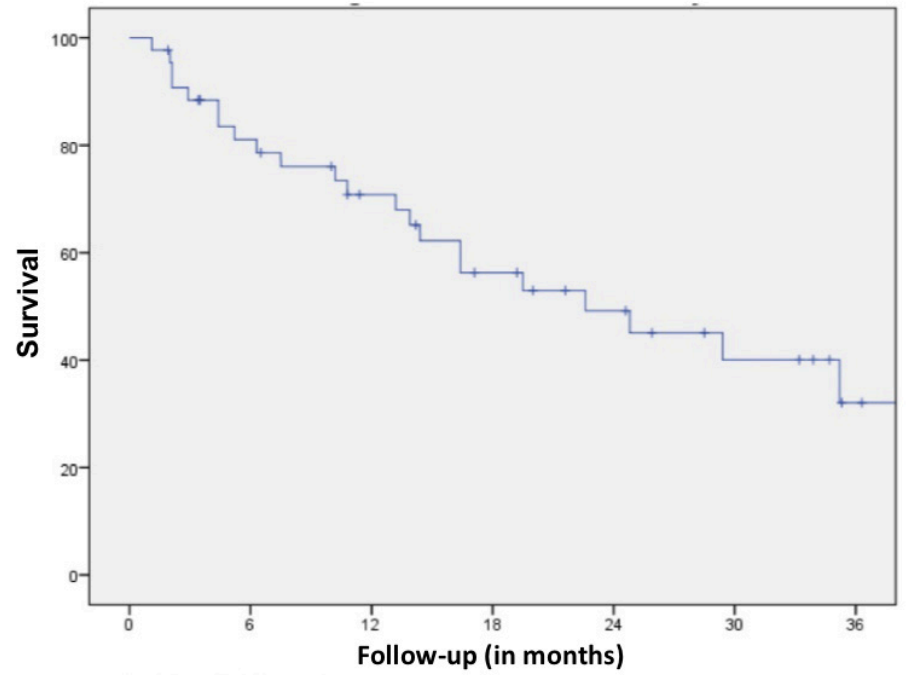

Figure 5. Salvage: disease-free survival. 


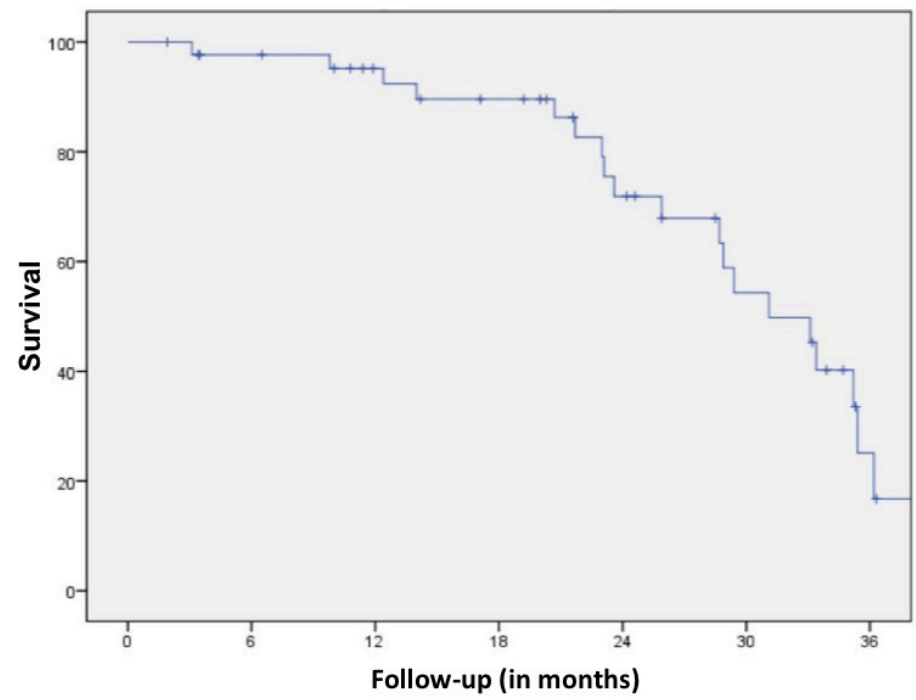

Figure 6. Salvage: specific survival.

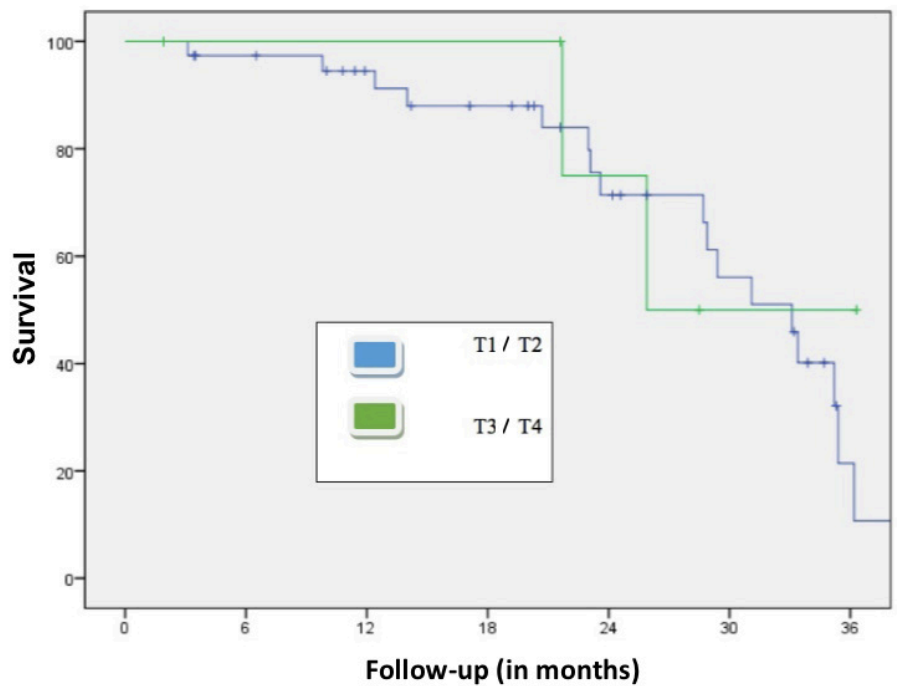

Figure 7. Salvage: specific survival according to staging at salvage procedures.

\section{Discussion}

The treatment approach for oropharyngeal tumors has been undergoing a significant change in paradigm due to the increase in the number of new cases associated with infection by HPV, with a higher incidence on young patients. The biggest challenge is achieving satisfactory oncological outcomes (local, regional, and distant control), preserving the speech and swallowing abilities. Traditionally, surgical treatment with negative margins has been the treatment of choice following radiation therapy ${ }^{12}$. Owing to high morbidity 
of surgical procedures in the oropharynx, surgical therapy has been losing ground to combination treatments of chemo- and radiation therapy.

Some authors have proposed minimally invasive approaches, such as the transoral laser ${ }^{13}$ and lateral transoral ${ }^{14,15}$ approaches. The difficulty to expose and obtain free margins in a limited field has been the main challenge facing these approaches. The emergence of TORS with the da Vinci system, which provides 3D visualization and magnification, allowed block resection of oropharyngeal tumors with safe surgical margins without transfacial and transmandibular surgical access, which significantly reduces associated morbidity compared to conventional surgery.

The characteristics of patients submitted to TORS at INCA in this period are similar to the ones found in the literature, such as male patients with average age of 61 years old, at stages T1 and T2, with tumors located in the oropharyngeal cavity, especially at the tonsil and base of tongue ${ }^{16}$. The vast majority of histopathological tumor types was squamous cell carcinoma, at a proportion comparable to the literature's $\mathrm{s}^{17}$.

For the statistics, we chose to distinguish patients submitted to surgery as first-line from those submitted to salvage surgery, aiming at releasing separate oncological outcomes that allow for the assessment of the actual benefits of TORS in both modalities of treatment - since in cases where the surgery is a salvage treatment, it was shown that exposure, as well as preoperative and intraoperative recognition of the extent of the disease is more difficult. This difference became clear upon observation of the number of recurrences, compromised margins and deaths associated with the recurrence, in addition to the disease-free and overall survival rates in patients submitted to salvage surgery compared to patients submitted to the surgery as first-line treatment.

The incidence of positive margins was of $4.62 \%$, which is compatible with other procedures described in the literature compared to the conventional transoral access ${ }^{17}$ and laser surgery ${ }^{18}$. However, upon assessment of our margins in salvage surgeries, we found a higher number of positive margins, especially due to the difficulty to define edges both in the preoperative, by means of tomography, and in the intraoperative, due to previous radiation therapy. This directly affects survival, when calculated, in particular upon comparison of first-line and salvage surgery. The follow-up period in this study varied between 12 and 56 months - an average of 23.5 months. Therefore, the outcomes must be evaluated as preliminary, as the ideal follow-up period would be of at least 5 years to allow for assessment of these patients' overall and disease-free survival - although the use of TORS in head and neck surgery is recent and the data in the literature are also preliminary. We have assessed survival of the patients submitted to TORS as primary surgery and salvage surgery separately. Survival of patients submitted to TORS as first-line treatment was of $86.2 \%$ in 24 months, which corresponds to our mean follow-up time. There is only one study carried out with initial tumors alone and robotic surgery as the single therapy with an overall survival rate of $100 \%$ in 18 months. However, the population was composed of only 30 cases, of which 4 presented recurrence ${ }^{19}$. In a systematic review of several papers published with oncological outcomes of TORS, although with different 
follow-up periods and mostly presenting less cases, the overall survival was of $91 \%$, whereas disease-free survival was of $90 \%{ }^{20}$.

In patients submitted to TORS as salvage therapy, we found a survival rate of $51.5 \%$, whereas the disease-free survival was of $42.2 \%$ - these results are comparable to the ones found for laser surgery. Laser and open surgery have presented an overall survival rate of approximately $51 \%$ and $64.5 \%$, respectively ${ }^{18,21}$. One prospective study has shown a survival rate of $74 \%$ with TORS compared to $43 \%$ in the group of patients submitted to open surgery ${ }^{22}$. Taking into account the significant amount of complications in conventional surgery in some series of up to $64 \%^{12}$, with similar or inferior oncological outcomes ${ }^{22}$. Upon assessment of immediate complications, the bleeding rate was considered to be low and safe, having been mostly clinically controlled. It was necessary to review hemostasis in only 3 cases; patients presenting trismus have also been rehabilitated with physiotherapy alone.

Swallowing and inhalation were assessed according to the dependence on the enteral feeding tube; $50 \%$ of patients required enteral support for longer than expected. The mean time of tube presence was 14.42 days, and the median was 10.5 days. By the end of the segment, all patients currently under control had their enteral tube removed. A multicenter study reported a rate of enteral feeding tube dependence of $5 \%$ after 1 year of follow-up ${ }^{16}$, which is lower than the rates reported for any other treatment ${ }^{23}$. Steiner et al. ${ }^{13}$, however, have indicated a rate of 1.6 over 44 months of follow-up. During our follow-up, all living patients are independent of the tube, where only 1 patient required the tube for 15 months, having had it removed and being currently on oral diet under supervision of the speech-therapy team.

In $29.55 \%$ of cases, tracheotomy was recommended in the perioperative period to prevent respiratory failure during postoperative due to the possibility of laryngeal and oropharyngeal swelling, or to prevent bronchoaspiration in case of bleeding. Only one patient required this as an emergency procedure due to respiratory failure following surgery. The period of tracheotomy was 29.77 days on average, with a median of 15 days. This data is similar to the data concerning the period of time of tube use - due to the large volume of patients in our service, we have weekly patient reviews, so that both tube and tracheotomy are usually removed during the same consultation. None of the patients currently under control is tracheostomized.

The hospitalization time of patients was, on average, 4.5 days, which is compatible with data from other major centers using TORS, and similar to published data concerning use of laser ${ }^{18}$.

The surgical time was kept from the moment the patient was under anesthesia. On average, the surgery lasted for 65.5 minutes - with 19.6 minutes for set-up and positioning of the robot and 45.8 minutes on the console, on average. This measurement is complex, as there are many extra-surgery variables that may affect the duration of surgery, such as the frozen section time etc. In addition, one case required microsurgical reconstruction with forearm tissue. Tables 14 and 15 compare our outcomes with those described in the literature. 
Table 14. Comparison of oncological outcomes.

\begin{tabular}{|c|c|c|c|c|c|c|c|}
\hline & Year & $\begin{array}{l}\text { Time of } \\
\text { Follow-up, in } \\
\text { months }\end{array}$ & $\mathbf{n}$ & $\begin{array}{l}\text { Locoregional } \\
\text { recurrence }\end{array}$ & $\begin{array}{l}\text { Disease-free } \\
\text { survival }\end{array}$ & $\begin{array}{l}\text { Overall } \\
\text { survival }\end{array}$ & $\begin{array}{l}\text { Positive } \\
\text { margins }\end{array}$ \\
\hline $\begin{array}{l}\text { INCA - RJ - Primary } \\
\text { Therapy }\end{array}$ & 2016 & 3 to 55 & 65 & $9 \%$ & $89 \%$ & $86 \%$ & 3 \\
\hline Olsen et al. ${ }^{24}$ & 2013 & 24 to 51 & 17 & $23 \%$ & $82 \%$ & $94 \%$ & 0 \\
\hline Mercante et al. ${ }^{25}$ & 2013 & 8 to 17 & 11 & $8 \%$ & $95 \%$ & $91 \%$ & 0 \\
\hline Weinstein et al. ${ }^{19}$ & 2012 & 18 to 31 & 25 & $5 \%$ & $92 \%$ & $98 \%$ & 1 \\
\hline Sinclair et al. ${ }^{26}$ & 2011 & 4 to 40 & 42 & $1 \%$ & $99 \%$ & $99 \%$ & 4 \\
\hline Moore et al. ${ }^{9}$ & 2009 & 1 to 16 & 33 & $4 \%$ & $91 \%$ & $99 \%$ & 0 \\
\hline Almeida et al. ${ }^{27}$ & 2015 & 74 & 410 & $10.50 \%$ & $94.00 \%$ & $91.00 \%$ & 57 \\
\hline Weinstein et al. ${ }^{16}$ & 2012 & 12 & 192 & - & - & - & 9 \\
\hline
\end{tabular}

Table 15. Morbidity.

\begin{tabular}{|c|c|c|c|}
\hline & $\mathbf{n}$ & $\begin{array}{l}\text { Dependence on } \\
\text { enteral tube }\end{array}$ & Complications \\
\hline INCA - RJ & 132 & $0 \%$ & 14 \\
\hline Olsen et al. ${ }^{24}$ & 17 & $3 \%$ & 0 \\
\hline Mercante et al. ${ }^{25}$ & 11 & $4 \%$ & 4 \\
\hline Weinstein et al. ${ }^{19}$ & 25 & $2 \%$ & 4 \\
\hline Sinclair et al. ${ }^{26}$ & 42 & $1 \%$ & 0 \\
\hline Moore et al. ${ }^{9}$ & 33 & $1 \%$ & 0 \\
\hline Almeida et al. ${ }^{27}$ & 410 & - & - \\
\hline Weinstein et al. ${ }^{16}$ & 192 & $5 \%$ & 29 \\
\hline
\end{tabular}

\section{Conclusion}

Transoral robotic surgery by means of the da Vinci system is oncologically safe, and it is possible to safely obtain clean margins both for treatment of oropharyngeal and supraglottal larynx tumors. All patients submitted to transoral robotic surgery had the speech and swallowing abilities rehabilitated in the long term, which, added to the low rate of relevant complications in our study, indicates low morbidity of the procedure. The absence of reportable deaths associated with the surgery is also relevant, as well as the absence of significant bleeding not clinically controllable, with the exception of the case of a patient with coagulopathy due to alcoholic liver disease. Therefore, we may conclude that robotic surgery is highly safe from the morbidity and oncological perspective. Furthermore, the significant reduction of the hospitalization period makes Transoral Robotic Surgery an important weapon for treatment 
of oropharyngeal and supraglottic larynx cancer under the Brazilian Unified Public Health System (SUS) at Instituto Nacional de Câncer - RJ.

The introduction of TORS in the Unified Public Health System at a traditionally pioneer hospital in new technology introduction for treatment of cancer in the country creates the possibility of qualification, improvement, and training of Head and Neck Surgeons in this novel therapy modality. In addition, it furthers dissemination across the country of this approach, already established as the treatment of choice for initial oropharyngeal and supraglottic larynx tumors, which makes TORS a national reality for treatment of malignant and benign oropharyngeal and supraglottic larynx tumors, including in the Unified Public Health System.

\section{References}

1. Kwoh YS, Hou J, Jonckheere EA, Hayati S. A robot with improved absolute positioning accuracy for CT guided stereotactic brain surgery. IEEE Trans Biomed Eng. 1988;35(2):153-60. http://dx.doi.org/10.1109/10.1354. PMid:3280462.

2. Davies B. A review of robotics in surgery. Proc Inst Mech Eng H. 2000;214(1):12940. http://dx.doi.org/10.1243/0954411001535309. PMid:10718057.

3. Hockstein NG, Nolan JP, O'Malley BW Jr, Woo YJ. Robotic microlaryngeal surgery: a technical feasibility study using the daVinci surgical robot and an airway mannequin. Laryngoscope. 2005;115(5):780-5. http://dx.doi.org/10.1097/01. MLG.0000159202.04941.67. PMid:15867639.

4. Weinstein GS, O'Malley BW Jr, Hockstein NG. Transoral robotic surgery: supraglottic laryngectomy in a canine model. Laryngoscope. 2005;115(7):1315-9. http:// dx.doi.org/10.1097/01.MLG.0000170848.76045.47. PMid:15995528.

5. O'Malley BW Jr, Weinstein GS, Snyder W, Hockstein NG. Transoral robotic surgery (TORS) for base of tongue neoplasms. Laryngoscope. 2006;116(8):1465-72. http:// dx.doi.org/10.1097/01.mlg.0000227184.90514.1a. PMid:16885755.

6. Hockstein NG, O'Malley BW Jr, Weinstein GS. Assessment of intraoperative safety in transoral robotic surgery. Laryngoscope. 2006;116(2):165-8. http://dx.doi. org/10.1097/01.mlg.0000199899.00479.75. PMid:16467698.

7. American Cancer Society. Cancer facts and figures 2009. Atlanta: American Cancer Society; 2009.

8. Machtay M, Perch S, Markiewicz D, Thaler E, Chalian A, Goldberg A, Kligerman M, Weinstein $\mathrm{G}$. Combined surgery and postoperative radiotherapy for carcinoma of the base of radiotherapy for carcinoma of the base of tongue: analysis of treatment outcome and prognostic value of margin status. Head Neck. 1997;19(6):494-9. http://dx.doi.org/10.1002/(SICI)1097-0347(199709)19:6<494::AIDHED6>3.0.CO;2-U. PMid:9278757.

9. Moore EJ, Henstrom DK, Olsen KD, Kasperbauer JL, McGree ME. Transoral resection of tonsillar squamous cell carcinoma. Laryngoscope. 2009;119(3):508-15. http:// dx.doi.org/10.1002/lary.20124. PMid:19235742. 
10. Boudreaux BA, Rosenthal EL, Magnuson JS, Newman JR, Desmond RA, Clemons L, Carroll WR. Robot-assisted surgery for upper aerodigestive tract neoplasms. Arch Otolaryngol Head Neck Surg. 2009;135(4):397-401. http://dx.doi.org/10.1001/ archoto.2009.24. PMid:19380364.

11. Genden EM, Desai S, Sung CK. Transoral robotic surgery for the management of head and neck cancer: a preliminary experience. Head Neck. 2009;31(3):283-9. http://dx.doi.org/10.1002/hed.20972. PMid:18972413.

12. Parsons JT, Mendenhall WM, Stringer SP, Amdur RJ, Hinerman RW, Villaret DB, Moore-Higgs GJ, Greene BD, Speer TW, Cassisi NJ, Million RR. Squamous cell carcinoma of the oropharynx: surgery, radiation therapy, or both. Cancer. 2002;94(11):2967-80. http://dx.doi.org/10.1002/cncr.10567. PMid:12115386.

13. Steiner W, Fierek $\mathrm{O}$, Ambrosch $\mathrm{P}$, Hommerich $\mathrm{CP}$, Kron M. Transoral laser microsurgery for squamous cell carcinoma of the base of the tongue. Arch Otolaryngol Head Neck Surg. 2003;129(1):36-43. http://dx.doi.org/10.1001/ archotol.129.1.36. PMid:12525192.

14. Holsinger FC, McWhorter AJ, Ménard M, Garcia D, Laccourreye O. Transoral lateral oropharyngectomy for squamous cell carcinoma of the tonsillar region: I. Technique, complications, and functional results. Arch Otolaryngol Head Neck Surg. 2005;131(7):583-91. http://dx.doi.org/10.1001/archotol.131.7.583. PMid:16027280.

15. Laccourreye O, Hans S, Ménard M, Garcia D, Brasnu D, Holsinger FC. Transoral lateral oropharyngectomy for squamous cell carcinoma of the tonsillar region, II: an analysis of the incidence, related variables, and consequences of local recurrence. Arch Otolaryngol Head Neck Surg. 2005;131(7):592-9. http://dx.doi. org/10.1001/archotol.131.7.592. PMid:16027281.

16. Weinstein GS, O'Malley BW Jr, Magnuson JS, Carroll WR, Olsen KD, Daio L, Moore EJ, Holsinger FC. Transoral robotic surgery: a multicenter study to assess feasibility, safety, and surgical margins. Laryngoscope. 2012;122(8):1701-7. http://dx.doi. org/10.1002/lary.23294. PMid:22752997.

17. Moore EJ, Olsen KD, Kasperbauer JL. Transoral robotic surgery for oropharyngeal squamous cell carcinoma: a prospective study of feasibility and functional outcomes. Laryngoscope. 2009;119(11):2156-64. http://dx.doi.org/10.1002/ lary.20647. PMid:19824067.

18. Grant DG, Salassa JR, Hinni ML, Pearson BW, Perry WC. Carcinoma of the tongue base treated by transoral laser microsurgery, part one: untreated tumors, a prospective analysis of oncologic and functional outcomes. Laryngoscope. 2006;116(12):2150-5. http://dx.doi.org/10.1097/01.mlg.0000244159.64179. fo. PMid:17146388.

19. Weinstein GS, Quon H, Newman HJ, Chalian JA, Malloy K, Lin A, Desai A, Livolsi VA, Montone KT, Cohen KR, O'Malley BW. Transoral robotic surgery alone for oropharyngeal cancer: an analysis of local control. Arch Otolaryngol Head Neck Surg. 2012;138(7):628-34. http://dx.doi.org/10.1001/archoto.2012.1166. PMid:22801885. 


\section{*Correspondence}

Ruy Gomes Neto

Instituto Nacional de Câncer (INCA)

Praça da Cruz Vermelha, 23, Centro

CEP 20230-120, Rio de Janeiro (RJ),

Brasil

Tel.: +55 (21) 98340-9595

E-mail: ruygomesneto@gmail.com

\section{Authors information}

RGN - Head \& Neck Surgeon Resident at Instituto Nacional do Câncer (INCA); FLD - Chairman of Head \& Neck Surgery Departament, Instituto Nacional do Câncer (INCA); RRMAL

- Director of Instituto Nacional do Câncer (INCA); UBT, EQF, TPF, ICS, $B C P, B A S$ and JML - Head \& Neck Surgeons at Instituto Nacional do Câncer (INCA).
20. Kelly K, Johnson-Obaseki S, Lumingu J, Corsten M. Oncologic, functional and surgical outcomes of primary Transoral Robotic Surgery for early squamous cell cancer of the oropharynx: a systematic review. Oral Oncol. 2014;50(8):696-703. http://dx.doi.org/10.1016/j.oraloncology.2014.04.005. PMid:24917389.

21. Nichols AC, Kneuertz PJ, Deschler DG, Lin DT, Emerick KS, Clark JR, Busse PW, Rocco JW. Surgical salvage of the oropharynx after failure of organ-sparing therapy. Head Neck. 2011;33(4):516-24. http://dx.doi.org/10.1002/hed.21480. PMid:20652974.

22. White H, Ford S, Bush B, Holsinger FC, Moore E, Ghanem T, Carroll W, Rosenthal E, Sweeny L, Magnuson JS. Salvage surgery for recurrent cancers of the oropharynx: comparing TORS with standard open surgical approaches. JAMA Otolaryngol Head Neck Surg. 2013;139(8):773-8. http://dx.doi.org/10.1001/jamaoto.2013.3866. PMid:23949352.

23. Machtay M, Moughan J, Trotti A, Garden AS, Weber RS, Cooper JS, Forastiere A, Ang KK. Factors associated with severe late toxicity after concurrent chemoradiation for locally advanced head and neck cancer: an RTOG analysis. J Clin Oncol. 2008;26(21):3582-9. http://dx.doi.org/10.1200/JCO.2007.14.8841. PMid:18559875.

24. Olsen SM, Moore EJ, Laborde RR, Garcia JJ, Janus JR, Price DL, Olsen KD. Transoral surgery alone for human-papillomavirus-associated oropharyngeal squamous cell carcinoma. Ear Nose Throat J. 2013;92(2):76-83. PMid:23460216.

25. Mercante G, Ruscito P, Pellini R, Cristalli G, Spriano G. Transoral robotic surgery (TORS) for tongue base tumours. Acta Otorhinolaryngol Ital. 2013;33(4):230-5. PMid:24043909.

26. Sinclair CF, McColloch NL, Carroll WR, Rosenthal EL, Desmond RA, Magnuson JS. Patient-perceived and objective functional outcomes following transoral robotic surgery for early oropharyngeal carcinoma. Arch Otolaryngol Head Neck Surg. 2011;137(11):1112-6. http://dx.doi.org/10.1001/archoto.2011.172. PMid:22106235.

27. Almeida JR, Li R, Magnuson JS, Smith RV, Moore E, Lawson G, Remacle M, Ganly I, Kraus DH, Teng MS, Miles BA, White H, Duvvuri U, Ferris RL, Mehta V, Kiyosaki K, Damrose EJ, Wang SJ, Kupferman ME, Koh YW, Genden EM, Holsinger FC. Oncologic outcomes after transoral robotic surgery: a multi-institutional study. JAMA Otolaryngol Head Neck Surg. 2015;141(12):1043-51. http://dx.doi. org/10.1001/jamaoto.2015.1508. PMid:26402479. 